\title{
Princípio da proporcionalidade e seu alcance no Direito Penal brasileiro
}

\section{Resumo}

O presente artigo tem por principal objeto o âmbito de aplicação do princípio $\mathrm{da}$ proporcionalidade no direito penal brasileiro. Assim, antes de adentramos no cerne principal da questão foram necessárias considerações a respeito da conceituação, da origem histórica e da configuração do princípio da proporcionalidade dentro do sistema normativo pátrio. No passo seguinte a abordagem é no sentido da relação e da relevância do princípio face à dignidade da pessoa no cenário constitucional brasileiro. Desenvolvemos a seguir o espectro de aplicabilidade e a importância do princípio
Ivan Motta

i.motta@terra.com.br

Doutor e Mestre em Direito pela Pontifícia

Universidade Católica de São Paulo. Professor do Centro Universitário FIEO.

Membro e diretor do Instituto Brasileiro de Ciências Criminais - IBCCRIM.

\section{Marilda Watanabe de Mendonça} marildawm@gmail.com

Mestranda em Direito pelo Centro

Universitário FIEO - em Direitos

Fundamentais. Procuradora do Estado

Consultora Jurídica na Secretaria de

Administração Penitenciária (São Paulo).

Recebimento em 21/02/2011 Aprovado em 02/09/2011

da proporcionalidade em sede de direito penal, levando em consideração os poderes constituídos do Estado: Legislativo, Executivo e Judiciário. Concluímos, ao final, pela integração da proporcionalidade em nosso sistema normativo, refletindo-se como garantia constitucional e instrumento de interpretação do direito penal.

\section{Palavras-chave}

Princípio da proporcionalidade.

Necessidade adequação. Razoabilidade.

Direito penal. 


\title{
Principle of proportionality and it's reach brazilian criminal law
}

\author{
Ivan Motta \\ Marilda Watanabe de Mendonça
}

\begin{abstract}
The main purpose of this article herein is the scope in which the proportionality principle in the Brazilian criminal law is applied. Therefore, prior to the discussion of the matter, it was necessary to take in consideration the concept, background and setting of the proportionality principle within the Brazilian law system. Next, the importance of the principle in view of one's dignity within the Brazilian constitutional scenario is brought to discussion, and later we point where it is applied and its materiality

in face of the criminal law, taking in consideration the power delegated to the Union: legislative, executive and judiciary branches. At last we conclude the proportionality integration in our law system, which reflects as constitutional guarantee and interpretation instrument of the criminal law.

Key words

Proportionality principle. Need of adequacy. Reasonability. Criminal law.
\end{abstract}




\section{Sumário}

Introdução

1 Metodologia

2 Princípio da Proporcionalidade:

considerações históricas, conceito e sub-princípios

3 Princípio da proporcionalidade e dignidade humana

4 O Legislativo e o princípio da proporcionalidade

5 O Judiciário e a dosimetria da pena

6 A execução proporcional da pena

Conclusão

Bibliografia 


\section{Introdução}

A interpretação do direito penal em face da Constituição é um tema instigante, ocupando os juristas brasileiros na busca do sentido ideal da justiça e figurando o princípio da proporcionalidade, dentre outros, como elemento fundamental nestas considerações.

É nítido, nas duas últimas décadas, a influência do direito português e alemão na construção da contemporânea doutrina constitucional penal.

O princípio da proporcionalidade não está positivado em nosso ordenamento jurídico, nos mesmos moldes que em outros Estados, porém tanto a doutrina como a jurisprudência sinalizam para sua aplicabilidade concreta e sua integração em nosso sistema.

De outro lado, incumbe ao hermeneuta verificar o alcance e os destinatários do princípio em estudo, sem olvidar da importância da dignidade humana no cenário constitucional e dos reflexos em toda a legislação.

O direito penal é a ciência que se ocupa do estudo de graves conflitos sociais, merecendo ser utilizado como último instrumento de contenção. As sanções decorrentes de sua aplicação geram restrições a direitos fundamentais, especialmente se vislumbrarmos as penas privativas de liberdade, cujo conteúdo tem efeito imediato sobre a liberdade das pessoas.

Por todo o exposto, busca-se a exata medida da aplicabilidade do princípio da proporcionalidade, seu conteúdo e destinatários.

\section{Metodologia}

Para a realização do presente trabalho problematizou-se a aplicação do princípio da proporcionalidade no direito penal brasileiro e foi utilizado o método dedutivo servindo-se de pesquisa bibliográfica e jurisprudencial para desenvolver o tema e dar fundamento à conclusão final do artigo.

A experiência diária nos processos de execução penal na Procuradoria Geral do Estado foi fundamental para a escolha do tema, pois foi possível constatar que nem sempre as decisões judiciais em sede penal refletiam o conteúdo do princípio. A rotina demonstrou que as restrições decorrentes da aplicação da lei penal devem ser sopesadas e compatibilizadas com o princípio da proporcionalidade. Neste sentido, observou-se, também que os reflexos da inobservância do princípio em foco extrapolam o âmbito do Judiciário e se espraiam no Legislativo e no Executivo, o 
primeiro, porque traça abstratamente os tipos e sanções penais e o segundo, porque participa significativamente na fase de execução de pena.

Partiu-se das premissas que a justa medida da condenação e da finalidade preventiva e retributiva da pena, necessariamente, devem passar pelo crivo da proporcionalidade, em vista da força do sistema normativo constitucional atual, da dignidade humana enquanto valor fundamental na aplicação do direito em geral e também porque o direito penal está inserido como última "ratio".

Desta forma, foi elaborada uma pesquisa bibliográfica sobre: i) o princípio da proporcionalidade, inserindo-se nesta busca, as origens, o conceito e quais os subprincípios que dele decorrem; ii) a relação da dignidade humana e do princípio da proporcionalidade; iii) os efeitos e a aplicabilidade do princípio da proporcionalidade no direito penal.

Para a realização desta espécie de pesquisa nos servimos da doutrina nacional e estrangeira, constantes em livros, periódicos e revistas especializadas. Em passo seguinte, observando a problemática no cenário nacional, detonada ora pela incompreensão, ora pela não aplicação do princípio da proporcionalidade, foi elaborada uma pesquisa jurisprudencial em revistas especializadas e também através de meios virtuais, utilizando-se como palavras chaves: "proporcionalidade - princípio da proporcionalidade - pena - fixação de pena - execução penal".

\section{Princípio da Proporcionalidade: considerações históricas, conceito e subprincípios.}

O princípio ${ }^{1}$ da proporcionalidade tem uma conotação atual de limitar o Estado "em benefício da garantia da integridade física e moral dos que lhes estão sub rogados"2 e sua origem é remota porque a própria Carta Magna ${ }^{3}$ de 1215 já é taxativa: “... O homem livre não deve ser punido por um delito menor, senão na medida desse delito, e por um grave delito ele deve ser punido de acordo com a gravidade

1 MELLO, Celso Antonio Bandeira de. Elementos de Direito Administrativo, SP: Revista dos Tribunais, 1986. Afirma o autor sobre princípio: “... é, por definição, mandamento nuclear de um sistema, verdadeiro alicerce dele, disposição fundamental que se irradia sobre diferentes normas compondo-lhes o espírito e servindo de critério para sua exata compreensão e inteligência, exatamente por definir a lógica e a racionalidade do sistema normativo, no que lhe confere a tônica e lhe dá sentido harmônico...”, p. 230.

2 GUerra filho, Willis Santiago. Teoria Processual da Constituição. São Paulo: Celso Bastos, 2000, p.75.

3 BARROSO, Luis Roberto. Interpretação e Aplicação da Constituição. 7. ed. rev. São Paulo: Saraiva, 2010, p. 224. 
do delito..."

Willis Santiago Guerra Filho ${ }^{4}$ comenta sobre a evolução histórica do princípio da proporcionalidade:

\begin{abstract}
...Durante a primeira metade do século em curso o princípio que ora tomamos em consideração foi tratado como atinente apenas à regulamentação da atividade policial, destinado a evitar excessos na sua prática. Por outro fado (sic), não se pode esquecer que primitivamente, Polizei, "polícia", é termo abrangente da atividade estatal como um todo e inclusive a própria noção de "Estado de direito", Rechtsstaat, vem mencionada pela primeira vez em obra tratando dessa matéria. Parece então provável que aqueles que primeiro atinaram para o emprego de um princípio da proporcionalidade nos assuntos de Estado já intencionassem uma aplicação abrangente, tal como hoje se preconiza...
\end{abstract}

Canotilho ${ }^{5}$ ao discorrer sobre o "o princípio da proibição do excesso" aduz:

O princípio da proporcionalidade dizia primitivamente respeito ao problema da limitação do poder executivo, sendo considerado como medida para as restrições administrativas da liberdade individual. É com este sentido que a teoria do estado o considera, já no século XVII, como máxima suprapositiva, e que ele foi introduzido, no séc. XIX, no direito administrativo como princípio geral do direito de polícia ( $\mathrm{cfr}$ art.272.o./1). Posteriormente o princípio da proporcionalidade em sentido amplo, também conhecido por princípio da proibição do excesso (Übermassverbot), foi erigido à dignidade de princípio constitucional... Discutido é o seu fundamento constitucional, pois enquanto alguns autores pretendem derivá-lo do princípio do estado de direito, outros acentuam que ele está intimamente conexionado com os direitos fundamentais.

E nesta esteira, para mencionar o direito comparado, é preciso consignar que a Constituição Portuguesa ${ }^{6}$ reconhece expressamente o princípio da proporcionalidade no seu art. 18, 2: “18.2..A lei só pode restringir os direitos, liberdades e garantias nos casos expressamente previstos na Constituição, devendo as restrições limitar-se ao necessário para salvaguardar outros direitos ou interesses constitucionalmente protegidos".

No Brasil, o princípio da proporcionalidade não tem assento constitucional de forma explícita, como na Alemanha e em Portugal, mas há normas esparsas indicativas da ideia de igualdade-proporcionalidade, característica dos Estados de

4 GUerra filHO, Willis Santiago. Teoria Processual da Constituição. São Paulo: Celso Bastos, 2000, p.77-78.

5 CANOTILHO, José Joaquim Gomes. Direito Constitucional e teoria da Constituição. 3. ed. Coimbra: Almedina, 1998, p. 261-262.

6 Constituição Portuguesa. Disponível em < http://www.parlamento.pt/legislação/Paginas/ constituicaorepublicaportuguesa $>$. Acesso em 25.11.2010. 
Direito $^{7}$. Paulo Bonavides, dentre os exemplos de restrições justificadas pela proporcionalidade no texto constitucional, cita expressamente os art. $5^{\circ}$, incisos, $\mathrm{X}$, XXV e $7^{\circ}, I V, V$ e XXI, entre outros.

Observe-se que não existe dispositivo constitucional que venha a dispor como o intérprete deve operar com as restrições de direito fundamental, figurando como destaque as palavras de Anna Candida da Cunha Ferraz : “... Não há regra geral específica sobre as limitações e as restrições aos direitos fundamentais que, em nosso sistema, como em qualquer outro, não são absolutos”.

Os limites e as restrições, quando não decorrem da norma específica definidora de determinado direito são, em regra, deduzidos dos princípios que regem o "sistema constitucional dos direitos fundamentais" (princípio da legalidade, com a reserva absoluta ou a proibição de legislação restritiva, princípio da igualdade etc)...

É certo também que o princípio da proporcionalidade é “o princípio da "justa medida”, e deriva da ideia de justiça, conectando-se à ideia de moderação, de equilíbrio", preservando-se o máximo do conteúdo de cada bem constitucional, da cada bem jurídico a ser analisado.

A doutrina nacional majoritária entende que o princípio da proporcionalidade deriva do princípio constitucional do devido processo legal (art. $5^{\circ}$., LIV) ${ }^{10}$, entretanto, Paulo Bonavides ${ }^{11}$, defende o posicionamento de que a proporcionalidade tem origem na igualdade, e estaria então inserido na ideia de Estado Democrático de Direito. O autor para conceituá-lo faz referência a Pierre Muller:

... Em sentido amplo... é a regra fundamental a que devem obedecer tanto os que exercem quando os que padecem o poder. Numa dimensão menos larga, o princípio se caracteriza pelo fato de presumir a existência de relação adequada entre um ou vários fins determinados e os meios com que são levados a cabo.

Nesta última acepção, entende Muller que há violação do princípio da proporcionalidade, com ocorrência de arbítrio, toda vez que os meios destinados a realizar um fim não são por si mesmos apropriados e ou quando a desproporção entre

7 BONAVIDES, Paulo. Curso de Direito Constitucional. 23. ed. São Paulo: Malheiros, 2008, p. 395.

8 FERrAZ, Anna Candida da Cunha. In: BITTAR, Eduardo C.B.; FERRAZ, Anna Candida da Cunha (Org.). Direitos Humanos Fundamentais: positivação e concretização. Osasco: Edifieo, 2006, p.172.

9 FIGUEIREDO, Mariana F. Direito à Saúde. Porto Alegre: Livraria do Advogado, 1. Edição, 2007, p. 121.

10 BUECHELE, Paulo Armínio Tavares. O princípio da Proporcionalidade e a Interpretação da Constituição. Rio de Janeiro: Renovar, 1999, p. 146.

11 BUECHELE, Paulo Armínio Tavares. O princípio da Proporcionalidade e a Interpretação da Constituição. Rio de Janeiro: Renovar, 1999, p. 362. 
meios e fim é particularmente evidente, ou seja, manifesta...

Inocêncio Mártires Coelho aduz sobre o conceito do princípio em estudo:

...Utilizado, de ordinário, para aferir a legitimidade das restrições de direitos - muito embora possa aplicar-se, também, para dizer do equilíbrio na concessão de poderes, privilégios ou benefícios - o princípio da proporcionalidade ou da razoabilidade, em essência consubstancia uma pauta de natureza axiológica que emana diretamente das ideias de justiça, equidade, bom senso, prudência, moderação...

Neste passo, consigne-se que independentemente de sua derivação, se trata de princípio fundamental para aplicação do direito de forma geral, especialmente em sede de direito penal, tendo vista que sob esta lente, o Estado, em caso de decisões condenatórias, tenderá a impor sanções, cuja restrição de direitos individuais é inexorável. Note-se que dentre as penas cominadas em nosso sistema normativa há as penas privativas de liberdade, que detém rigor indiscutível, face a restrição do bem colocado sob sanção.

Na aplicação do direito penal, o princípio da proporcionalidade é de relevância, pois a aferição da justa medida da condenação e da finalidade preventiva e retributiva da pena, necessariamente devem ser analisados sob este aspecto.

Sobre o tema destacam-se as palavras de Alberto Silva Franco ${ }^{12}$ ao comentar o art. $1^{\circ}$. do Código Penal: “... O princípio da proporcionalidade exige que se faça um juízo de ponderação sobre a relação existente entre o bem que é lesionado ou posto em perigo (gravidade do fato) e o bem de que pode alguém ser privado (gravidade da pena)...”.

O princípio da proporcionalidade, na doutrina brasileira e alemã, se desdobra nos sub-princípios: adequação, necessidade e proporcionalidade stricto sensu ou razoabilidadade ou máximo sopesamento, dos quais depende a solução dos casos concretos de aplicação. A adequação é o " meio certo para levar a cabo um fim baseado no interesse público"; necessidade, ou exigibilidade, deve ser entendida, como a " medida restritiva indispensável" do próprio direito e que não pode ser substituída por outra menos gravosa ${ }^{13}$.

O sub-princípio da razoabilidade, por sua vez, é critério de avaliação do ato restritivo na perspectiva das consequências que gera sobre a esfera pessoal de quem foi afetado, ficando vedada a exagerada afetação do direito fundamental, protegendo-se, em conseguinte os direitos de outrem. Seu aspecto chave, segundo Paulo

12 FRANCO, Alberto Silva. Código Penal e sua Interpretação. Coordenação Alberto Silva Franco e Rui Stocco. São Paulo: Revista dos Tribunais, 8 $^{a}$. Edição, 2007, p. 50

13 BUECHELE, Paulo Armínio Tavares. O princípio da Proporcionalidade e a Interpretação da Constituição. Rio de Janeiro: Renovar, 1999, p. 124-130. 
Armínio Tavares Buechele é a "ponderação, a relação custo-benefício", ou seja, a verificação das vantagens e desvantagens para o cidadão"14. Luís Roberto Barroso ${ }^{15}$ adverte sobre a possibilidade de se utilizá-lo como expressão fungível do princípio da proporcionalidade:

... Sem embargo da origem e do desenvolvimento diversos, um e outro abrigam os mesmos valores subjacentes: racionalidade, justiça, medida adequada, senso comum, rejeição aos atos arbitrários ou caprichosos. Por essa razão, razoabilidade e proporcionalidade são conceitos próximos o suficiente para serem intercambiáveis...

Destaquem se também as colocações de Suzana de Toledo Barros ${ }^{16}$ :

... o juiz quando considera adequada a relação entre determinada restrição e o fim a que se destina, ou mesmo quando reconhece a inexistência de outro meio menos gravoso que pudesse conduzir ao mesmo resultado, nem por isso está a chancelar uma providência que imponha ônus demasiados ao cidadão Há situações em que é plenamente possível identificar um desequilíbrio na relação meio fim, sem que se possa concluir pela desnecessidade da providência legislativa porque não está em causa a existência de outra medida menos lesiva, mas sim a precedência de um bem ou interesse sobre outro....

Feitas estas considerações é interessante ressaltar que a razoabilidade, pode também ter uma concepção autônoma e ligada à garantia do devido processo legal, que por sua vez tornou-se uma das fontes principais dos norte americanos nas últimas décadas ${ }^{17}$. Luís Roberto Barroso afirma que há duas grandes fases no due process of law, a fase processual e a substantiva. Essa última se expressa como "importante instrumento de defesa dos direitos individuais ensejando o controle do arbítrio do Legislativo e da discricionariedade governamental" ${ }^{18}$.

Sobre as diferentes terminologias acentua Carlos A. P. Souza e Patrícia P.Sampaio $^{19}$ :

14 BUECHELE, Paulo Armínio Tavares. O princípio da Proporcionalidade e a Interpretação da Constituição. Rio de Janeiro: Renovar, 1999, p. 132.

15 BARROSO, Luis Roberto. Interpretação e Aplicação da Constituição. S.P:Ed. Saraiva, 7. Edição Revista, 2010, p. 374.

16 TOLEDO, Suzana de Toledo. O Princípio da Proporcionalidade e o Controle de Constitucionalidade das Leis Restritivas de Direitos Fundamentais. Brasília: Brasília Jurídica, 1996, p. 80.

17 BARROSO, Luis Roberto. Interpretação e Aplicação da Constituição. S.P:Ed. Saraiva, 7. Edição Revista, 2010 p. 224.

18 BARROSO, Luis Roberto. Interpretação e Aplicação da Constituição. S.P:Ed. Saraiva, 7. Edição Revista, 2010, p. 225.

19 SOUZA, Carlos Affonso Pereira de, SAMPAIO, Patrícia Regina Pinheiro. O princípio da razoabilidade e o princípio da proporcionalidade: uma abordagem constitucional. Disponível em < http://www.pucrio.br/sobrepuc/depto/direito/pet_jur/cafpatrz.html>. Acesso em 27.08.2011, p. 13-14. 
... A tradução do conteúdo do princípio da proporcionalidade nem sempre encontra-se explicitado sob esta epígrafe, motivo pelo qual procederemos a uma breve explanação acerca de outras denominações porventura utilizadas para transmitir esta mesma noção e a uma análise de seu real conteúdo.

A doutrina alemã, a título de ilustração, utiliza indistintamente as nomenclaturas proporcionalidade e proibição de excesso. Os americanos são mais caros ao uso do termo razoabilidade, o qual, nada obstante, é também usado em certas ocasiões com conteúdo diverso ao da proporcionalidade, embora se completem...

A relação, portanto, entre razoabilidade e proporcionalidade é bastante tênue, podendo ser eleito o critério histórico como diferencial, ou seja, razoabilidade para os norte americanos ${ }^{20}$ e proporcionalidade em sentido estrito para os alemães ${ }^{21}$. Não se pode desprezar, porém, um ponto de identidade entre os conceitos, na medida em que tanto a razoabilidade, como proporcionalidade em sentido estrito,

20 SOUZA, Carlos Affonso Pereira de, SAMPAIO, Patrícia Regina Pinheiro. O princípio da razoabilidade e o princípio da proporcionalidade: uma abordagem constitucional. Disponível em <http://www.pucrio.br/sobrepuc/depto/direito/pet_jur/cafpatrz.html>. Acesso em 27.08.2011. Afirmam os autores sobre razoabilidade: “... Incorporado à Constituição norte-americana de 1787 através das emendas $5^{a}$ e 14, o referido princípio tornou-se prontamente objeto constante de intenso trabalho doutrinário e jurisprudencial, principalmente no que tange à interpretação dada pela Suprema Corte americana, pois se hoje o mesmo pôde alcançar o reconhecimento e o prestígio que lhe são devidos, tal se deve ao enunciado flexível sobre o qual foi esculpido e às possibilidades abertas pelo case system, emblema maior do sistema da Common Law. (...) Assume, por fim, a cláusula do devido processo legal a função de filtro da atividade estatal, seja normativa ou administrativa, cumprindo destacar o fato de que a garantia processual contida no enunciado do due process of law não restou excluída com este avanço para a análise de mérito da atuação do Estado, uma vez que ambos os sentidos (processual e substantivo) podem e devem coexistir para a total aplicação das conquistas aferidas pela afirmação do princípio do devido processo legal...”, p.7-8.

21 SOUZA, Carlos Affonso Pereira de, SAMPAIO, Patrícia Regina Pinheiro. O princípio da razoabilidade e o princípio da proporcionalidade: uma abordagem constitucional. Disponível em <http://www.pucrio.br/sobrepuc/depto/direito/pet_jur/cafpatrz.html>. Acesso em 27.08.2011. Dizem os autores sobre proporcionalidade:" ... A origem e desenvolvimento do princípio da proporcionalidade encontra-se intrinsecamente ligado à evolução dos direitos e garantias individuais da pessoa humana, verificada a partir do surgimento do Estado de Direito burguês na Europa. Desta forma, sua origem remonta aos séculos XII e XVIII, quando na Inglaterra surgiram as teorias jusnaturalistas propugnando ter o homem direitos imanentes a sua natureza e anteriores ao aparecimento do Estado e, por conseguinte, conclamando ter o soberano o dever de respeitá-los. Pode-se afirmar que é durante a passagem do Estado Absolutista - em que o governante tem poderes ilimitados - para o Estado de Direito, que pela primeira vez emprega-se o princípio da proporcionalidade, visando a limitar o poder de atuação do monarca face aos súditos (...) Coube à Alemanha, após beber na teoria da limitação do poder de polícia do Direito Administrativo francês, a formulação atual do princípio da proporcionalidade em âmbito constitucional, notadamente no campo dos direitos fundamentais (...) A promulgação da Lei Fundamental de Bonn representa, assim marco inaugural do princípio da proporcionalidade em âmbito constitucional, ao colocar o respeito aos direitos fundamentais como núcleo central de toda a ordem jurídica....”, p. 11-12. 
são instrumentos de preservação e garantia de direitos fundamentais, por isso, a possibilidade de utilizá-los como expressões equivalentes.

\section{Princípio da proporcionalidade e dignidade humana}

Discorrer sobre o princípio da proporcionalidade e dignidade humana é analisar em que medida este se aplica para que a dignidade seja preservada. Decorre naturalmente da aplicação do princípio em tela a restrição de algum direito e nesta seara, não se pode conceber face à fundamentalidade dos bens jurídicos preservados pelo direito penal, a menor hipótese de infringência à dignidade humana.

Observe-se que as restrições de direito fundamental merecem uma concreta análise e reflexão porque o excesso aviltará a Constituição em seu postulado mais precioso: a dignidade.

Eventuais restrições devem ser balizadas em critérios bem delineados, evitandose assim a desproporcionalidade, seja na criação da norma legal, seja na aplicação desta por parte do Executivo ou do Judiciário.

Eduardo Ribeiro Moreira ${ }^{22}$ em artigo sobre o tema afirma que existem três formas de restrição de direitos fundamentais:

...1. A restrição contida na própria Constituição ( ao dispor sobre um direito fundamental constitucionalmente expresso, ela traça as hipóteses acerca de sua restrição; são portanto, exceções previstas na regra constitucional).

2. A restrição constitucionalmente autorizada, ou seja, prevista por lei, que foi mencionada e autorizada pela Constituição, ao final da disposição do direito fundamental.

3. Restrições aos direitos fundamentais por lei, inobstante não serem nem expressas na Constituição nem expressamente decorrentes do texto constitucional...

Neste estudo o destaque se volta não somente para as restrições previstas na Constituição, mas especialmente para aquelas que decorrem da lei e de norma regulamentadora. Sobre as últimas, ressalte-se que somente poderão permanecer no ordenamento jurídico se compatíveis com o texto constitucional, consequentemente justificar-se-iam pelo princípio da razoabilidade ${ }^{23}$ e da supremacia da Constituição.

22 MOREIRA, Eduardo Ribeiro. A teoria das restrições dos direitos fundamentais, in Revista de Direito Constitucional e Internacional n.69, 2009, p. 95

23 RIBEIRO Eduardo. A teoria das restrições dos direitos fundamentais, in Revista de Direito Constitucional e Internacional n.69, 2009, p. 99. 
Restrições desta última espécie ocorrem sempre quando existem relações desiguais, que a doutrina denomina de relações especiais de sujeição, como por exemplo, no caso da Administração de um presídio e os presos ou ainda, entre a Administração Pública e seus servidores ${ }^{24}$.

No que tange à dignidade humana é preciso consignar que se trata de um dos princípios informadores do Estado brasileiro e se encontra expressamente mencionado como fundamento da República, ex-vi do art. $1^{\circ}$, inciso III da Constituição.

Jorge Miranda ${ }^{25}$ diz que a dignidade é fonte ética de todos os direitos fundamentais, com conotação de unidade valorativa do sistema constitucional, de forma que é inconcebível o sacrifício de tal valor em favor do grupo social ou da Administração, propriamente dita. Diante da lição, o autor conclui que se trata de postulado ético em que o ser humano, o homem, na acepção ampla do termo, deve ser tomado como um fim em si mesmo, e pode exigir prestações do Estado, que lhe assegurem o mínimo para a existência digna.

A conceituação de dignidade humana, segundo Ingo Sarlet ${ }^{26}$ é difícil porque se trata de um conceito impreciso e necessita de uma delimitação pela práxis constitucional, de forma a ser apurada em cada caso concreto, afirmando também:

... A dignidade, como qualidade intrínseca da pessoa humana, é algo que simplesmente existe, sendo irrenunciável e inalienável, na medida em que constitui elemento que qualifica o ser humano como tal e dele não pode ser destacado, de tal sorte que não se pode cogitar na possibilidade de determinada pessoa ser titular de uma pretensão a que lhe seja concedida a dignidade. Esta, portanto, como elemento integrante e irrenunciável da natureza da pessoa humana, é algo que se reconhece, respeita e protege, mas não que possa ser criado ou the possa ser retirado, já que existe em cada ser humano como algo que lhe é inerente... ${ }^{27}$

24 MOREIRA, ibidem. O autor discorre sobre o tema: “... Essa é uma situação que não tem encontrado grande destaque no debate constitucional brasileiro e é outro momento sensível à restrição dos direitos fundamentais conhecido como relação especial de poder e também chamado de relação especial de sujeição, em que, pela situação posta, se justificaria em tese, uma proeminência de uma situação especial em detrimento dos direitos fundamentais previstos genericamente...” ( p. 101-102).

25 MIRANDA, Jorge. Manual de Direito Constitucional: direitos fundamentais. Coimbra: Coimbra Editora, 2. ed. 1998, vol. 4, p. 166-167.

26 SARLET, Ingo Wolfgang. A eficácia dos direitos fundamentais. Uma teoria geral dos direitos fundamentais na perspectiva constitucional. Porto Alegre: Livraria do Advogado, 10. ed., 2009, p. 100.

${ }^{27,28}$ SARLET, Ingo Wolfgang. A eficácia dos direitos fundamentais. Uma teoria geral dos direitos fundamentais na perspectiva constitucional. Porto Alegre: Livraria do Advogado, 10. edição, 2009, p. 100-101. 
Adriana Zawada Mello ${ }^{28}$ em análise ao conteúdo da dignidade humana aduz:

... No tocante aos aspectos substanciais da dignidade tutelada, Nobre Junior identifica com acerto seus dois vértices fundamentais: a impossibilidade de degradação do ser humano e o direito a uma existência material mínima. Como se vê, eles representam, respectivamente, a esfera moral e a esfera material e social do ser humano...

É bastante interessante também a investigação do significado da dignidade humana no ordenamento jurídico brasileiro, tendo em vista sua positivação no texto constitucional e imediato impacto em toda a legislação face o princípio da verticalidade das normas.

José Afonso da Silva afirma se tratar de um valor supremo ${ }^{29}$ e Ingo Sarlet entende que se trata de um princípio informador, detendo portanto uma função instrumental e de grande valia na hermenêutica, porque "serve de parâmetro para a aplicação, interpretação e integração não apenas dos direitos fundamentais e do restante das normas constitucionais, mas de todo o ordenamento jurídico", de forma a torná-lo coerente ${ }^{30}$.

Anna Cândida da Cunha Ferraz ${ }^{31}$ afirma no mesmo sentido:

... O princípio da dignidade humana, ou da dignidade da pessoa humana, alcança no contexto da Constituição de 1988, espaço ímpar ... preordena a compreensão e a interpretação dos direitos sediados no núcleo central da Constituição, a organização dos poderes e do Estado e particularmente, a atuação dos poderes na conformação legislativa dos direitos... e na aplicação das normas constitucionais e infraconstitucionais consagradoras, limitadoras ou restritivas de direitos...

Portanto, há um estreito elo entre o princípio da proporcionalidade e o princípio da dignidade humana, porque se o homem é o principal destinatário da Constituição vigente, é necessário ao intérprete preservar a dignidade humana, notadamente quando da necessidade da restrição de direitos fundamentais, o que comumente ocorre em sede de direito penal.

28 MELLO, Adriana Zawada. Direitos Sociais, Igualdade e Dignidade da Pessoa Humana, in Revista Mestrado em Direito da UNIFIEO, n. 1, 2007, p. 110.

29 SILVA, José Afonso. A dignidade da pessoa humana como valor supremo da democracia, in Revista de Direito Administrativo, Rio de Janeiro, n. 212, p. 92, abr./jun. 1998. Esclarece o autor sobre o tema: “... Não é apenas um princípio da ordem jurídica, mas o é também da ordem política, social, econômica e cultural. Daí sua natureza de valor supremo, porque está na base de toda a vida nacional..." (p.92).

30 SILVA, José Afonso. A dignidade da pessoa humana como valor supremo da democracia, in Revista de Direito Administrativo, Rio de Janeiro, no. 212, p. 107.

31 SILVA, José Afonso. A dignidade da pessoa humana como valor supremo da democracia, in Revista de Direito Administrativo, Rio de Janeiro, no. 212, p. 131. 


\section{O Legislativo e o princípio da proporcionalidade}

Na seara de direito penal é de aplicabilidade imprescindível o princípio da proporcionalidade, pois expressa-se como garantia ao cidadão e instrumento de interpretação ao Estado, nas três esferas de poder.

Não se despreza que todas as vezes que adentramos na área criminal o princípio da anterioridade da lei penal é uma das linhas mestras a serem utilizadas pelo hermeneuta, pois "não há crime sem lei anterior que o defina, nem pena sem prévia cominação legal”.

Entretanto, este princípio que se encontra inscrito no art. $1^{\circ}$ do Código Penal não esgota a aplicação da lei penal nos tribunais. A norma penal sempre contém dois preceitos. O primeiro que tipifica a conduta e o segundo, conhecido como preceito secundário que impõe a pena ${ }^{32}$.

O legislador, ao criar a lei penal, além de observar as determinações constitucionais do ponto de vista formal ${ }^{33}$, necessariamente deve levar em consideração o princípio da proporcionalidade, a fim de que não crie tipos penais distanciados da realidade, ou seja, não criminalize "fatos" que devem ser apreciados em âmbito diverso, dispensando a intervenção do direito penal.

Ivan Martins Motta ${ }^{34}$ ao analisar a concepção material do tipo penal adverte: “... Sendo os tipos penais modelos abstratos de condutas proibidas, é impossível evitarse que tenham um alcance muito amplo, maior do que é desejado...”.

Em consequência, algumas condutas insignificantes, socialmente adequadas e até socialmente necessárias podem ser abrangidas pelo tipo penal...

Como limitar esta ampla abrangência do tipo penal de crime e evitar que as pessoas tenham que justificar condutas que são aceitas pela comunidade em que vive?

32 FRANCO, Alberto Silva. Código Penal e sua Interpretação. Coordenação Alberto Silva Franco e Rui Stocco. São Paulo: Revista dos Tribunais, 8. ed., 2007. Comenta o autor sobre o tema:"... O princípio da legalidade implica que o fato constitutivo de delito apareça descrito na própria lei de um modo exaustivo. Quer dizer, exige que a lei emanada do Parlamento descreva, mediante a indicação dos diversos caracteres da conduta delitiva, a matéria de proibição, a fim de que os limites entre o lícito e o ilícito não fiquem à mercê da decisão judicial... Mas o necessário grau de determinação não é só exigível ao preceito primário da norma penal. Não deixaria de ofender ao princípio da legalidade o preceito sancionatório, que se mostrasse indeterminado, isto é, sem menção da espécie da quantidade de pena cominada...” (p.56).

33 CABRAL, Francisco de Assis. Constituição Federal Interpretada. Coord. Anna Candida da Cunha Ferraz,, Barueri: Manole, 2010. Sobre os aspectos formais da criação da lei penal observem-se os dispositivos constitucionais dos art. 61 ao 68, que tratam sobre competência e processo legislativo ordinário, p. 465-494.

34 MOTTA, Ivan Martins. Estrito Cumprimento de Dever Legal e Exercício Regular de Direito. São Paulo: Juarez de Oliveira, 2000, p. 18. 
Vico Mañas diz, com exatidão, que esse desiderato só pode ser atingido atribuindose ao tipo penal, ao lado do caráter formal, um sentido material...

Alberto Silva Franco ${ }^{35}$ comentando sobre os limites da lei penal diz:

... a intervenção penal tem limites materiais, isto é não guarda pertinência quando os bens jurídicos podem ser garantidos por outros controles sociais formais menos gravosos. Nesse caso, a atividade criminalizadora contraria o princípio da proporcionalidade...

Desta feita, é possível deduzir que a criação dos tipos penais merece a observância da intervenção mínima, enquanto princípio, mormente se observarmos que "as disposições que restringem a liberdade humana não podem ultrapassar o limite do necessário"36.

Maura Roberti ${ }^{37}$ afirma sobre o tema:

... o princípio da intervenção mínima está implicitamente contemplado em nosso ordenamento jurídico, pois sua inferência é indiscutível, em face de uma exegese conivente com os ideais a serem alcançados por um Direito Penal Liberal comprometido com um Estado Democrático de Direito...

Luigi Ferrajoli ${ }^{38}$ ao discorrer sobre direito penal mínimo tece as seguintes considerações:

... o direito penal mínimo, quer dizer, condicionado e limitado ao máximo, corresponde não apenas ao grau máximo de tutela das liberdades dos cidadãos frente ao arbítrio punitivo, mas também a um ideal de racionalidade e de certeza...

Ressalte-se, então que a compreensão do direito penal como "ultima ratio"39 é instrumentalizada, pelo Legislativo, com a efetiva obediência à proporcionalidade enquanto regra matriz para a criação dos tipos e sanções penais. Justa medida e prevenção do arbítrio em direito penal são alcançadas também na fase de criação da norma legal, porque incumbe ao legislador estabelecer "penas proporcionais à

35 MOTTA, Ivan Martins. Estrito Cumprimento de Dever Legal e Exercício Regular de Direito. São Paulo: Juarez de Oliveira, 2000, p. 40-41.

36 ROBERTI, Maura. A intervenção mínima como princípio no direito penal brasileiro. Porto Alegre: Sérgio Antonio Fabris, 2001, p. 68.

37 ROBERTI, Maura. A intervenção mínima como princípio no direito penal brasileiro. Porto Alegre: Sérgio Antonio Fabris, 2001, p. 69.

38 FERrAJOLI, Luigi. Direito e Razão. Teoria do Garantismo Penal. São Paulo: Revista dos Tribunais, 2. ed., 2006, tradução Ana Paulo Zomer Sica, Fauzi Hassan Choukr, Juarez Tavares, Luiz Flávio Gomes, p. 102.

39 FRANCO, Alberto Silva. Código Penal e sua Interpretação. Coordenação Alberto Silva Franco e Rui Stocco. São Paulo: Revista dos Tribunais, 8. ed., 2007, p.40. 
gravidade do delito" ${ }^{\prime 40}$.

$\mathrm{Na}$ realidade a ponderação de valores passa pela fase de elaboração da lei, sob pena de não se atingir a finalidade da justiça e a restrição do direito ser senão inconstitucional, desproporcional ${ }^{41}$. Insista-se na ideia de que o direito penal é sempre subsidiário porque a criminalização de todas as condutas não é solução para a insegurança que assola a sociedade.

Sobre o tema também nos adverte René Ariel Dotti ${ }^{42}$ :

... O princípio da intervenção penal minima foi recepcionado pela Constituição através do $₫ 2^{\circ}$ do art. $5^{\circ}$ : “Os direitos e garantias expressos nesta Constituição não excluem outros decorrentes do regime e dos princípios por ela adotados, ou dos tratados internacionais em que a República Federativa do Brasil seja parte". O princípio em análise tem a sua raiz no art. $8^{\circ}$ da Declaração Dos Direitos do Homem e do Cidadão (Paris,1789), ao proclamar que a lei deve estabelecer "penas estrita e evidentemente necessárias".

A compatibilização entre a letra e o espírito das leis fundamentais internas e as declarações internacionais constitui exigência de uma ordem jurídica universal...

Konrad Hesse ${ }^{43}$ diz:

... Assim, deve uma restrição de direito fundamental estar ajustada ao perigo, que deve ser combatido, deve, no quadro do procedimento penal, uma intervenção intencionada na integridade corporal... guardar relação adequada com a gravidade do crime, e é impondo o respeito aos direitos fundamentais gerais de ter em conta o princípio da proporcionalidade...

Assim, o Legislador deve atentar à lesividade do fato e à necessidade de sua previsão como fato típico, como crime e simultaneamente deve cominar uma sanção

40 FRANCO, Alberto Silva. Código Penal e sua Interpretação. Coordenação Alberto Silva Franco e Rui Stocco. São Paulo: Revista dos Tribunais, 8. ed., 2007, p. 50.

41 DIAS, Jorge Figueiredo Dias. Direito Penal - Parte Geral. São Paulo: Revista dos Tribunais, 2. ed. Coimbra Editora, 2007. Afirma o autor sobre a dogmática jurídico penal:”... a legitimação da intervenção penal não pode hoje ser vista como unicamente advinda de qualquer ordem transcendente e absoluta de valores, mas tem que ser coada por critérios funcionais de necessidade (e de consequente utilidade) social. Daí também que a pena não mais possa fundarse em exigência de retribuição, ou expiação da culpa, mas apenas como propósitos de prevenção ... geral e especial...”, p.31.

42 DOTTI, René Ariel. Princípios Fundamentais do Direito Penal Brasileiro, Artigo publicado no Bulletin de la Societá internationale de défense sociale pour une politique criminelle bumaniste - CAHIERS DE DEFENSE SOCIALE. Edição em homenagem a Louk Hulsman. Ano 2003. Disponível em <HTTP>www.buscalegis.ufsc.br/revistas/index.php/buscalegis>, p.12 . Acesso em 27.11.2010.

43 HESSE, Konrad. Elementos de direito constitucional da República Federal da Alemanha. Trad Luis Afonso Heck. Porto Alegre: Sergio Fabris, 1998, 256-257, nota 319. 
compatível com a reprovação social da conduta. Um sistema normativo constitucional que tem por paradigma a dignidade humana necessita urgentemente de um poder legiferante atuante que possa proteger efetivamente a coletividade, sem ser desproporcional por ser muito rigoroso ou ainda muito brando na criação das normas penais.

O tratamento legislativo dispensado a algumas omissões e ações tem gerado uma certa sensação de impunidade, como a exemplo dos crimes de colarinho branco, ante os benefícios constantes da Lei 9.714/98, que possibilita a aplicação de penas alternativas ${ }^{44}$. De outro lado, destaquem-se as considerações de Lênio Streck ${ }^{45}$ sobre o tratamento abrandado ao Estatuto do Idoso:

... Mais recentemente, temos o episódio envolvendo o Estatuto do Idoso (Lei 10.741/03), cujo art. 94 rebaixa à categoria de "crimes de menor potencial ofensivo" todos os crimes previstos na citada Lei, desde que a pena, abstratamente considerada, não ultrapasse a 4 anos, o que faz com que crimes como "deixar de prestar assistência a idoso", com resultado morte, e "expor a perigo a integridade e a saúde, física ou psíquica do idoso, submetendo a condições desumanas", com a sujeição deste a trabalho escravo e disso resultando lesão corporal grave, sejam levados aos Juizados Especiais Criminais,ficando os criminosos aptos, neste caso, a receberem a benesse da transação penal, através da qual, mediante o pagamento de uma ou algumas cestas básicas, a persecutio criminis estará esgotada...

O princípio em estudo é de extrema relevância para a análise de alguns paradoxos existentes em nossa legislação penal, como por exemplo: a) seis anos de reclusão para o homicídio simples (art. 121) e dez anos de reclusão para venda de cosmético adulterado (art. $273 \$ 1^{\circ}$ ); b) doze anos de reclusão para homicídio quali-

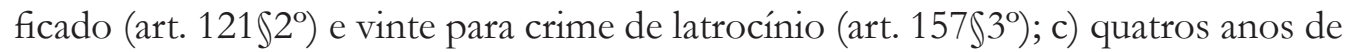
reclusão para lesão corporal seguida de morte (art. $129 \$ 3^{\circ}$ ) e cinco anos e quatro meses para roubo agravado (art.157 $\left.\int 2^{\circ}\right)^{46}$. Não se esgotam os exemplos, mas é de se consignar que em todos estes exemplos o bem jurídico "vida" foi minorado em relação à incolumidade pública e ao patrimônio.

44 STRECK, Lênio Luiz. "A dupla face do princípio da proporcionalidade e o cabimento de mandado de segurança em matéria criminal: superando o ideário liberal-individualista-clássico", Disponível em <http://leniostreck.com.br/index, p. 7.> . Acesso em 27.11.2010.

45 STRECK, Lênio Luiz. "A dupla face do princípio da proporcionalidade e o cabimento de mandado de segurança em matéria criminal: superando o ideário liberal-individualista-clássico", Disponível em <http://leniostreck.com.br/index, p. 7.> . Acesso em 27.11.2010.

46 FRANCO, Alberto Silva. Código Penal e sua Interpretação. Coordenação Alberto Silva Franco e Rui Stocco. São Paulo: Revista dos Tribunais, 8. ed., 2007. O autor comenta nesta obra às fls. 51 e 52 estas e outras situações análogas. 


\section{O Judiciário e a dosimetria da pena}

O conteúdo do princípio da proporcionalidade também vincula o Judiciário, na medida em que o julgador figura entre os destinatários do princípio em análise, porque lhe incumbe impor ao autor pena proporcional à gravidade do delito ${ }^{47}$, ao aplicar a lei penal.

Alberto Silva Franco nos adverte que dentre as questões que permeiam este tema se encontra a dificuldade de se estabelecer quais os critérios da proporcionalidade, da ponderação. E nessa esteira, ante a inexistência formal e positivada destes há de se buscar um "juízo de adequabilidade entre a gravidade do preceito sancionatório e a danosidade social do comportamento criminoso" 48 .

Luigi Ferrajoli escreve sobre o tema:

... o problema da justificação do tipo e da medida da pena aplicáveis em cada caso, da mesma forma que o dos limites máximos da pena, independentemente do delito cometido, é um problema moral e político, quer dizer, exclusivamente de legitimação externa. Este problema é por sua vez, suscetível de ser decomposto em três subproblemas: o da predeterminação pelo legislador do tipo e da medida máxima e mínima da pena para cada tipo de delito; o da determinação por parte do juiz da natureza e medida da pena para cada delito concreto; o da pós-determinação, na fase executiva, da duração a pena efetivamente sofrida...

O espaço para a discricionariedade do juiz na aplicação da pena reside principalmente na fase de análise sobre as expressões abstratas como "participação de menor importância", "motivo fútil ou torpe" "abuso de autoridade", "abuso de poder" (29\$1, 61, II, “a”, “f”, “g” do Código Penal), entre outras, bem como as cláusulas abertas constantes do art. 59 do Código Penal, também conhecidas como circunstâncias judiciais ${ }^{49}$, cuja redação é a seguinte:

Art. 59: $\mathrm{O}$ juiz atendendo à culpabilidade, aos antecedentes, à conduta social, à personalidade do agente, aos motivos, às circunstâncias e consequências do crime, bem como ao comportamento da vítima, estabelecerá, conforme seja necessário e suficiente para reprovação e prevenção do crime.

A individualização da pena é determinação constitucional ( art. $5^{\circ}$., XVLVI da Constituição) e René Ariel Dotti ${ }^{50}$ tece as seguintes considerações:

47 FRANCO, Alberto Silva. Código Penal e sua Interpretação. Coordenação Alberto Silva Franco e Rui Stocco. São Paulo: Revista dos Tribunais, 8. ed., 2007, p. 50.

48 FRANCO, Alberto Silva. Código Penal e sua Interpretação. Coordenação Alberto Silva Franco e Rui Stocco. São Paulo: Revista dos Tribunais, 8. ed., 2007, p.51.

49 MiRABETE Júlio Fabrini. Código Penal interpretado. São Paulo: Atlas, 2001, p. 325.

50 DOTTI, René Ariel. Princípios Fundamentais do Direito Penal Brasileiro, Artigo pu- 
... Não se admite a capacidade criminal da pessoa jurídica em face da exigência da culpabilidade que atua como fundamento e limite da pena. O primado nulla poena sine culpa é extraído do princípio constitucional da dignidade da pessoa humana (art. $1^{\circ}$, III) e das normas penais que estabelecem a responsabilidade em função da culpa (lato

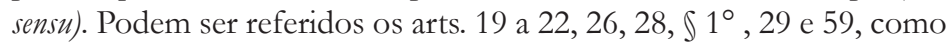
paradigmáticos para indicar que o sistema penal brasileiro não admite a responsabilidade objetiva. É relevante salientar que dois desses dispositivos (29 e 59) expressamente aludem à culpabilidade como um endereço de indagação obrigatória do juiz para definir o grau de participação criminosa e fixar a pena...

Ressalte-se que uma interpretação gramatical do art. 59 do Código Penal indica a intenção do legislador na utilização do princípio ante a expressão "conforme seja necessário e suficiente para a reprovação e prevenção do crime”. Trata-se então de questão absolutamente valorativa e intrinsicamente ligada à ideia de equidade.

O Supremo Tribunal Federal ${ }^{51}$ em acórdam cujo relator era o ministro Sepúlveda Pertence decidiu:

... A exigência de motivação da individualização da pena - hoje garan-
tia constitucional do condenado (CF, arts. $5^{\circ}$., XLVI e 93 , IX) - não
se satisfaz com a existência na sentença de frases, ou palavras quais-
quer , a pretexto de cumpri-la: a fundamentação há de explicitar a sua
base empírica; essa, de sua vez, há de guardar relação de pertinência,
legalmente adequada, com a exasperação da sanção penal, que visou
justificar..."

Luigi Ferrajoli ${ }^{52}$ em estudo sobre a equidade da pena esclarece que no Código Penal italiano existem critérios de valoração exemplificativos como: natureza, espécie, os meios, o objeto e o tempo do crime; a gravidade do dano; os modelos de vida do autor do crime, etc. Na sequência, advertindo que estes não são exaustivos, esclarece: “... por causa de seu inevitável caráter genérico e valorativo, carecem de condições para vincular o juiz, a quem, no entanto, são remetidos sempre os juízos de valor sugeridos por aqueles critérios".

São esses juízos de valor os que formam a discricionariedade fisiológica da interpretação judicial. Sobre eles seria inútil pretender controles certos e objetivos.

blicado no Bulletin de la Societá internationale de défense sociale pour une politique criminelle bumaniste - CAHIERS DE DEFENSE SOCIALE. Edição em homenagem a Louk Hulsman. Ano 2003. Disponível em $<$ HTTP $>$ www.buscalegis.ufsc.br/revistas/index.php/buscalegis $>$. Consulta em 27.11.2010.

51 BRASIL. Supremo Tribunal Federal. Habeas Corpus 69.419- Diário da Justiça de 28-08-1992, disponível no endereço eletrônico < HTTP :www. STF.jus.br/portal/jurisprudência >, consulta em 27.11.2010.

52 FERRAJOLI, Luigi. Direito e Razão. Teoria do Garantismo Penal. São Paulo: Revista dos Tribunais, 2.. ed., 2006, tradução Ana Paulo Zomer Sica, Fauzi Hassan Choukr, Juarez Tavares, Luiz Flávio Gomes, p. 372-373. 
Só se pode conceber duas ordens de indicações: uma incidente no método e outra, no conteúdo. No plano do método, pode-se e deve-se pretender que os juízos nos quais se apóia a conotação não sejam vagos, senão explícitos e fundamentados em argumentações pertinentes que evidenciem as inevitáveis premissas valorativas dos mesmos... entre estas ... respeito à pessoa e pelo reconhecimento de sua dignidade...

Destaque-se, novamente, que a dignidade humana e o princípio da proporcionalidade aparecem como vetor principal no sopesamento dos fatores que fundamentam a aplicação da lei penal. E operada a subsunção à norma, incumbe ao juiz a escolha da pena e esta se apresenta como uma segunda fase da aplicação judicial do princípio mencionado.

Há de se observar, então, os incisos do art. 59 do Código Penal, de forma que o juiz deve escolher dentre as penas ${ }^{53} \operatorname{cominadas}^{54}$ qual é a aplicável (I); a quantidade da pena ( II); o regime de cumprimento ${ }^{55}$ (IV) e se cabível, a substituição da pena privativa de liberdade por outra espécie de pena ${ }^{56}$.

\section{O Superior Tribunal de Justiça ${ }^{57}$ já se manifestou acerca do tema:}

53 MIRABETE Júlio Fabrini. Código Penal interpretado. São Paulo: Atlas, 2001. Ensina o autor sobre o art. 33 do Código Penal: “... Por força da Lei 7.209, de 11.07.84... classificam-se elas em privativas de liberdade ( reclusão e detenção), restritivas de direito ( prestação pecuniária, perda de bens e valores, prestação de serviços à comunidade ou a entidades públicas, interdições temporárias de direito) e multa...” (p. 250)

54 FRANCO, Alberto Silva. Código Penal e sua Interpretação. Coordenação Alberto Silva Franco e Rui Stocco. São Paulo: Revista dos Tribunais, 8. ed., 2007. Sobre o tema afirma o autor: “... No processo de fixação da pena, a primeira das providências a ser adotada pelo juiz é inquestionavelmente a da escolha da pena aplicável. Ao compor o preceito sancionatório o legislador poderá estabelecer uma cominação simples, cumulada ou alternativa de penas. É evidente que, nos casos em que a pena for de aplicação simples ou cumulada, não tem o juiz nenhuma faculdade de escolha. Já não ocorre o mesmo na hipótese de alternatividade (ou pena detentiva ou pena pecuniária, por exemplo), que demanda uma explícita definição judicial...” (p.347-348)

55 MIRABETE Júlio Fabrini. Código Penal interpretado. São Paulo: Atlas, 2001. Afirma o autor sobre o art. 33 do Código Penal e os regimes de cumprimento de pena:'... Adotando o sistema progressivo na execução das penas privativas de liberdade estabelece a lei três regimes: fechado, semi aberto e aberto... Por regra especial, a pena de prisão simples, aplicada ao autor de contravenção, só pode ser cumprida em regime semi-aberto ou aberto ( art. $6^{\circ}$., caput da LCP)...”( p.252).

56 FRANCO, Alberto Silva. Código Penal e sua Interpretação. Coordenação Alberto Silva Franco e Rui Stocco. São Paulo: Revista dos Tribunais, 8. ed., 2007. Abordando a questão consta de tal obra: “... se a quantidade da pena privativa de liberdade aplicada não superar os quatro anos, nos crimes dolosos, ou se se tratar de condenação por crime culposo, deverá o magistrado, obrigatoriamente... analisar se estão preenchidos os requisitos de natureza objetiva e subjetiva para a substituição por pena restritiva de direitos ou multa (v.art.44)...” (p.349).

57 BRASIL. Superior Tribunal de Justiça. AgRg no HC 157642 / SP.Agravo regimental no habeas corpus 2009/0247039-1. Relator Ministro Celso Limongi. Julgamento em 26.10.2010. Disponível em<http://www.stj.jus.br/SCON/jurisprudencia/doc>. Acesso em 26.11.2010. 
"Ementa: AGRAVO REGIMENTAL. HABEAS CORPUS. EXECUÇÃO PENAL. CRIME HEDIONDO.TRÁFICO DE DROGAS. CRIME PRATICADO NA VIGÊNCIA DAS LEIS Ns 11.343/06 E 11.464/07. ESTABELECIMENTO DE REGIME PRISIONAL DIVERSO DO FECHADO.POSSIBILIDADE. REPRIMENDA INFERIOR A QUATRO ANOS, RECONHECIMENTO DEPRIMARIEDADE E AUSÊNCIA DE CIRCUNSTÂNCIAS JUDICIAIS DESFAVORÁVEIS. COMANDO LEGAL QUE DEVE SER COMPATIBILIZADO COM OS PRINCÍPIOS DA ÍNDIVIDUALIZAÇÃO DA PENA E PROPORCIONALIDADE...”

Gilmar Ferreira Mendes ${ }^{58}$ ao tratar sobre o âmbito de proteção da pena diz:

... a aplicação da pena e a determinação de sua medida hão de se louvar pela ideia de necessidade. Daí aceitar-se que tanto as teorias de prevenção geral como as de prevenção especial acabam por ter um papel na definição dos bens tutelados e na medida da pena.

A concepção puramente retributiva, observa Figueiredo, nada tem a dizer em matéria de finalidade da pena, cabendo-lhe, sim, como observado, o mérito de revelar a essencialidade do princípio da culpa e do significado deste para o problema da finalidade da pena...

Por todo o exposto, entende-se que a escolha da pena, quer seja em razão da sua quantidade, quer seja em razão de sua qualidade (privativa de liberdade, multa, restritiva de direito etc), necessariamente passa pelos filtros da proporcionalidade e consequentemente pelo princípio da dignidade humana e este por sua vez é supedâneo do princípio da humanidade da pena, tanto que o nosso sistema constitucional o positivou.

Disciplina o art. $5^{\circ}$, inciso XLVII da Constituição, que não haverá penas de morte, exceto em caso de guerra declarada (a); de caráter perpétuo (b); de trabalhos forçados (c); de banimento (d); cruéis (e). Note-se que a proibição de penas cruéis deve ser entendida como a sanção que expõe o condenado ao castigo físico, à dor, ao sofrimento, logo, compromete a dignidade humana ${ }^{59}$.

Além disso, os princípios constitucionais da legalidade, da anterioridade da lei penal (art.5 $5^{\circ}$ XXXIX), da retroatividade da lei penal mais benéfica (art. $5^{\circ}$, XL), da individualização e progressão da pena (art. $5^{\circ}$,XLVI), da presunção de inocência (art. 5 $5^{\circ}$ LVII ), bem como o direito ao respeito à integridade física e moral dos presos ( art. $5^{\circ}$, XLIX) e todos os demais princípios constitucionais implícitos e

58 MENDES, Gilmar Ferreira et al. Curso de Direito Constitucional. São Paulo: Saraiva, 5. ed., 2010, p. 706.

59 FERrAZ FILHO, José Francisco. Constituição Federal Interpretada. Coord. Anna Candida da Cunha Ferraz...Barueri: Manole, 2010, p. 38. 
explícitos, são parâmetros bastante concretos para que o juiz possa operar a escolha da pena e posteriormente acompanhar sua execução de forma constitucional e em consonância com a proporcionalidade.

\section{A execução proporcional da pena}

Na seara da execução da pena o princípio da proporcionalidade também é de ser observado, não se desprezando que sua inobservância pode gerar consequências incompatíveis com a sistemática constitucional.

Gilmar Ferreira Mendes ${ }^{60}$ ao analisar a inclusão da progressão de regime nos casos de crimes hediondos afirma:

... Em verdade a Lei dos Crimes Hediondos continha uma incongruência grave, pois ao mesmo tempo que repelia a progressividade, admitia o livramento condicional desde que cumpridos $2 / 3$ da pena(CP, art. $83, \mathrm{~V})$. Tinha-se, pois, o retorno à vida social sem que tenha havido progressão do regime, com a reintrodução gradual do condenado na vida em sociedade...

... a fórmula abstrata do art. $2^{\circ} \$ 1^{\circ}$., da Lei $8.072 / 90$, que vedava a progressão aos crimes hediondos...

Como explicar, com algum grau de plausibilidade, que o crime de tortura considerado de especial gravidade... possa ter a progressão de regime expressamente admitida e os demais crimes considerados hediondos estejam excluídos desse benefício?...

Merece também análise o tratamento dispensado à perda de dias remidos no atual ordenamento jurídico. A remição de pena é benefício previsto na Lei de Execuções Penais, em seu art. 126, na proporção de um dia de pena por três de trabalho. O cumprimento das penas privativas de liberdade se dá sob dois aspectos: o administrativo e o judicial.

Em caso de falta grave, por exemplo, prevê o art. 127 da Lei de Execuções Penais a perda dos dias remidos. Diante de tal dispositivo há questionamento frente à constitucionalidade do dispositivo em comento, tendo em vista que a coisa em julgada é garantia constitucional e nestes casos em concreto o juízo da execução que anteriormente havia declarada a remição e consequentemente perdoado parte da pena, em razão da ocorrência da falta grave, decreta a perda dos dias remidos.

Simultaneamente, surgem os reflexos em sede administrativa, face o poder disciplinar da Administração. Neste passo, fica o sentenciado, também, sujeito às san-

60 MENDES, Gilmar Ferreira et al. Curso de Direito Constitucional. São Paulo: Saraiva, 5. ed., 2010, p. 716. 
ções administrativas do art. 53 da Lei de Execuções Penais: advertência verbal; repreensão; suspensão ou restrição de direitos (art. 41, parágrafo único); isolamento na própria cela, ou em local adequado, nos estabelecimentos que possuam alojamento coletivo, observado o disposto no art. 88 da mesma lei e inclusão no regime disciplinar diferenciado. Note- se, portanto, a penalização do sentenciado nas duas esferas, judicial e administrativo, em total dissonância com o princípio da vedação da dupla punição pelo mesmo fato ${ }^{61}$.

Veio à lume este único exemplo, mas outras situações, como os "livramentos condicionais cautelares", as "regressões cautelares",63, a configuração das "faltas graves" ${ }^{64}$ e outros fatos, em sede de execução de penal, merecem um novo dimen-

${ }^{61}$ NUCCI, Guilherme de Souza. Manual de Direito Penal. São Paulo: Revista dos Tribunais, 4.ed., $2^{a}$.tiragem, 2008. Afirma o autor sobre o princípio da vedação da dupla punição pelo mesmo fato: “... Quer dizer ninguém deve ser processado duas vezes pela prática da mesma infração penal. Tal garantia está prevista implicitamente na Convenção Americana sobre Direitos Humanos ( art. $8^{\circ}$., no.4)...", p. 76.

62 FRANCO, Alberto Silva. Código Penal e sua Interpretação. Coordenação Alberto Silva Franco e Rui Stocco. São Paulo: Revista dos Tribunais, 8. ed., 2007. Anota jurisprudência sobre o tema em CD-Rom que acompanha a obra: "Deferido pleito de progressão ao regime aberto, constitui decisão extra petitum a concessão cautelar de livramento condicional, uma vez que, havendo requerimento certo, determinado e único, ele não pode ser convertido em benefício diverso, sem audiência do interessado e manifestação da Defesa Técnica, sob pena de ferir os princípios do contraditório e da correlação entre o pedido e a decisão, especialmente nessa hipótese em que a conversão é mais gravosa, pois, ao contrário do que sucede na regressão, se revogado o livramento, não será computado como cumprimento de pena o tempo em que esteve solto o sentenciado, sendo certo que, se, por inexistência de casa de albergado ou de estabelecimento similar, a concessão de albergue domiciliar não se mostrar aconselhável, pode e deve ser indeferida, nada impedindo, entretanto, que, caso concedida, sejam impostas condições mais rigorosas para seu cumprimento" (TACRIM-SP - 13. ${ }^{a}$ C. - Agr. em Execução 1.316.771/6 - Rel. Lopes da Silva - j. 10.09.2002 - RJTACRIMSP 63/35).

${ }^{63}$ FRANCO, Alberto Silva. Código Penal e sua Interpretação. Coordenação Alberto Silva Franco e Rui Stocco. São Paulo: Revista dos Tribunais, 8. ed., 2007. Anota jurisprudência sobre o tema em CD-Rom que acompanha a obra: "Muito embora a construção pretoriana venha admitindo sustação cautelar do regime prisional semi-aberto, cujas regras foram violadas em razão de falta disciplinar grave, nenhuma dúvida porém que a medida não se justifica quando há notícia de simples atraso de três dias na reapresentação de saída temporária, com o sentenciado logo apresentando-se ao Juízo da Execução antes que a ocorrência a este tivesse sido comunicada, exibindo documentos para justificar o atraso cuja validade há de ser apreciada no bojo do procedimento administrativo que se determinou instaurar. O retorno sponte propria, poucos dias após a falta, revela, quando menos, arrependimento e desejo de se reincorporar ao cumprimento da pena, circunstância que não se pode deixar de levar em conta" (TACRIM-SP - RA 1.029.609/8 - Rel. Aroldo Viotti). "A falta grave, a ensejar a regressão do regime prisional do apenado, deve ficar comprovada. Hipótese em que o agravante teve o seu nome mencionado como suposto agressor, não sendo viável presumir-se contra ele, devendo ser desconsiderada a acusação do cometimento de tal falta. Cassada a decisão que determinou a regressão de regime prisional, do semi-aberto para o fechado. Agravo provido" (TJRS - Ag. - Rel. Alfredo Foerster - j. 27.05.99-RJTJRGS 196/146)

${ }^{64}$ A Lei de Execuções Penais ( Lei 7.210/1984) em seu 118 prevê: “A execução da pena privativa 
sionamento face as afirmações expendidas neste artigo. Motivos de ordem metodológicos e a riqueza do tema justificam a mera menção a estas questões e a necessidade de uma abordagem à parte.

$\mathrm{Na}$ realidade, na órbita administrativa, depara-se com a grande margem de discricionariedade que detém a Administração na execução da sanção penal, tendo em vista a abstração dos conceitos que envolvem o tema.

Por todo o exposto, o princípio da proporcionalidade integra nosso sistema normativo e deve ser observado em sede de direito penal, seja na criação, seja na aplicação da norma legal, pelo Judiciário e pelo Executivo.

A vinculação aos poderes constituídos é patente e reflete-se como garantia do cidadão de ter um direito penal justo e ao Estado, serve como instrumento fundamental de interpretação.

\section{Conclusão}

O princípio da proporcionalidade embora não positivado na Constituição Federal tem relação intrínseca com o Estado de Direito, pois independentemente de decorrer do principio da igualdade ou do devido processo legal, detém normatividade.

A dignidade humana tem uma especial posição na Constituição Brasileira, pois se trata de um valor supremo que permeia todo o ordenamento jurídico e enquanto fundamento de Estado, também há de ser considerada quando da aplicação do principio da proporcionalidade.

O conteúdo principal da proporcionalidade reside na ideia da justa medida, da ponderação, de justiça. É possível afirmar que tem conotação de garantia constitucional porque protege as pessoas contra os eventuais abusos da aplicação do direito penal e fornece ao Estado, na pessoa dos poderes constituídos, Legislativo, Executivo e Judiciário, preciosa ferramenta de interpretação.

$\mathrm{Na}$ área de direito penal há interesses conflitantes que demandam a aplicação da norma legal, em situações onde é possível identificar, por exemplo, o interesse da comunidade em preservar a segurança, em um extremo e no outro, o direito indivi-

de liberdade ficará sujeita à forma regressiva, com a transferência para qualquer dos regimes mais rigorosos, quando o condenado: I - praticar fato definido como crime doloso ou falta grave; II - sofrer condenação, por crime anterior, cuja pena, somada ao restante da pena em execução, torne incabível o regime (art. 111). $\int 1^{\circ} \mathrm{O}$ condenado será transferido do regime aberto se, além das hipóteses referidas nos incisos anteriores, frustrar os fins da execução ou não pagar, podendo, a multa cumulativamente imposta. $\int 2^{\circ}$ Nas hipóteses do inciso I e do parágrafo anterior, deverá ser ouvido previamente o condenado." 
dual daquele, que se submete à lei penal e necessariamente sofrerá uma restrição de direitos, em caso de condenação.

A observância dos três subprincípios na ponderação maximizam o manejo da proporcionalidade. A adequação entendida como a realização do interesse público com os fins perseguidos; a necessidade, representada pela absoluta indispensabilidade da restrição e inexistência de outro meio menos gravoso; e a proporcionalidade em sentido estrito, com a aferição da justa medida. Todos estes sub-princípios são relevantes para a aferição da justiça.

O legislador ao criar a norma penal deve necessariamente atentar para a lesividade do fato, dentro do contexto social e a necessidade de sua previsão como fato típico. Caso entenda pela criminalização da conduta deve cominar uma sanção compatível com a reprovação social desta.

O julgador, por sua vez, ao aplicar a lei penal tem em suas mãos, tanto na fase da individualização da pena, quanto na execução elementos para balizar um julgamento proporcional. Os princípios constitucionais da humanidade da pena (art. $5^{\circ}$, XLVII), da legalidade (art. 5 , II) e seus desdobramentos, da anterioridade da lei penal (art. $5^{\circ}$, XXXIX), da retroatividade da lei penal mais benéfica (art. $5^{\circ}, \mathrm{XL}$ ), da individualização e progressão da pena (art. $5^{\circ}$,XLVI), da presunção de inocência (art. $5^{\circ}$, LVII), bem como o direito ao respeito à integridade física e moral dos presos (art. $5^{\circ}$, XLIX) e outros princípios são balizas concretas para que o juiz possa operar a escolha da pena, acompanhar sua execução de forma constitucional e em consonância com as diretrizes da proporcionalidade.

A Administração, por sua vez, também tem valiosa ferramenta de realização da justiça em sede de direito penal, mormente na fase de execução de penas, quando do exercício do poder disciplinar. A Lei de Execuções Penais tem diversos dispositivos com grande carga de abstração e que necessariamente demandam a aplicação concreta do principio da proporcionalidade.

Concluímos, enfim, que a realização da dignidade humana, enquanto principio fundamental do Estado Democrático de Direito, se encontra invariavelmente conectada a aplicação da proporcionalidade, especialmente em sede de direito penal, tendo em vista que nesta seara, as restrições de direito figuram como elemento caracterizador de todas as sanções. 


\section{Bibliografia}

BARROSO, Luis Roberto. Interpretação e Aplicação da Constituição. São Paulo: Saraiva, 7. ed., Revista, 2010.

BONAVIDES, Paulo. Curso de Direito Constitucional. São Paulo: Malheiros, 23. ed., 2008.

BRASIL. Superior Tribunal de Justiça. AgRg no HC 157642 / SP.Agravo regimental no habeas corpus 2009/0247039-1. Relator Ministro Celso Limongi. Julgamento em 26.10.2010. Disponível em <http://www. stj.jus.br/SCON/jurisprudencia/doc.>. Acesso em 12.11.2010.

BUECHELE, Paulo Armínio Tavares. O princípio da Proporcionalidade e a Interpretação da Constituição. Rio de Janeiro: Renovar, 1999.

CABRAL, Francisco de Assis. Constituição Federal Interpretada. Coord. Anna Candida da Cunha Ferraz,, Barueri: Manole, 2010.

CANOTILHO, José Joaquim Gomes. Direito Constitucional e teoria da Constituição, Coimbra: Almedina, 3. ed., 1998.

DIAS, Jorge Figueiredo Dias. Direito Penal - Parte Geral. São Paulo: Revista dos Tribunais, 2. ed. Coimbra Editora, 2007.

DOTTT, René Ariel. Princípios Fundamentais do Direito Penal Brasileiro, Artigo publicado no Bulletin de la Societá internationale de défense sociale pour une politique criminelle bumaniste - CAHIERS DE DEFENSE SOCIALE. Edição em homenagem a Louk Hulsman. Ano 2003. Disponível em < HTTP:www.buscalegis ufsc.br/revistas/index.php/buscalegis> . Acesso em 27.11.2010.

FERRAJOLI, Luigi. Direito e Razão. Teoria do Garantismo Penal.. Tradução Ana Paulo Zomer Sica, Fauzi Hassan Choukr, Juarez Tavares, Luiz Flávio Gomes São Paulo: Revista dos Tribunais, 2. ed., 2006.

FERrAZ, Anna Candida Cunha, "Aspectos da positivação dos direitos fundamentais na Constituição de 1988”, in Direitos Humanos Fundamentais: positivação e concretização. Org. Eduardo C.B.Bittar e Anna Candida da Cunha Ferraz. Osasco: Edifieo, 2006.

FERRAZ FILHO, José Francisco. Constituição Federal Interpretada. Org. Costa Machado.Barueri: Manole, 2010. FRANCO, Alberto Silva. Código Penal e sua Interpretação. Coordenação Alberto Silva Franco e Rui Stocco. São Paulo: Revista dos Tribunais, 8. ed., 2007.

GUERRA FILHO, Willis Santiago. Teoria Processual da Constituição. São Paulo:Celso Bastos, 2000.

HESSE, Konrad. Elementos de direito constitucional da República Federal da Alemanha. Trad Luis Afonso Heck. Porto Alegre: Sergio Fabris, 1998.

MELLO, Adriana Zawada. Direitos Sociais, Igualdade e Dignidade da Pessoa Humana, in Revista Mestrado em Direito da UNIFIEO, no. 01, 2007, p.97-116.

MELLO, Celso Antonio Bandeira de. Elementos de Direito Administrativo, São Paulo: Revista dos Tribunais, 1986.

MENDES, Gilmar Ferreira et al. Curso de Direito Constitucional. São Paulo: Saraiva, 5. ed., 2010.

MIRABETE Júlio Fabrini. Código Penal interpretado. São Paulo: Atlas, 2001.

. Execução Penal. São Paulo: Atlas, 11.ed., 2004

MIRANDA, Jorge. Manual de Direito Constitucional : direitos fundamentais. Coimbra: Coimbra Editora, 2. ed., 1998, vol. 4.

MOREIRA, Eduardo Ribeiro. A teoria das restrições dos direitos fundamentais, in Revista de Direito Constitucional e Internacional n.69, 2009.

MOTTA, Ivan Martins. Estrito Cumprimento de Dever Legal e Exercício Regular de Direito. São Paulo: Juarez de Oliveira, 2000.

NUCCI, Guilherme de Souza. Manual de Direito Penal. São Paulo: Revista dos Tribunais, 4.ed., $2^{a}$.tiragem, 2008.

ROBERTI, Maura. A intervenção mínima como princípio no direito penal brasileiro. Porto Alegre: Sérgio Antonio Fabris, 2001.

SARLET, Ingo Wolfgang. A eficácia dos direitos fundamentais. Uma teoria geral dos direitos fundamentais na perspectiva constitucional. Porto Alegre: Livraria do Advogado, 10ª Edição, 2009.

SILVA, José Afonso. A dignidade da pessoa humana como valor supremo da democracia, in Revista de Direito Administrativo, Rio de Janeiro. 
SOUZA, Carlos Affonso Pereira de, SAMPAIO, Patrícia Regina Pinheiro. O princípio da razoabilidade e o princípio da proporcionalidade: uma abordagem constitucional. Disponível em < http://www.pucrio. $\mathrm{br} /$ sobrepuc/depto/direito/pet_jur/cafpatrz.html>. Acesso em 27.08.2011

STRECK, Lênio Luiz. A dupla face do princípio da proporcionalidade e o cabimento de mandado de segurança em matéria criminal: superando o ideário liberal-individualista-clássico . Disponível em $<$ http://leniostreck.com.br/index, . Acesso em 27.11.2010.

TOLEDO, Suzana de Toledo. O Princípio da Proporcionalidade e o Controle de Constitucionalidade das Leis Restritivas de Direitos Fundamentais. Brasília: Brasília Jurídica, 1996. 